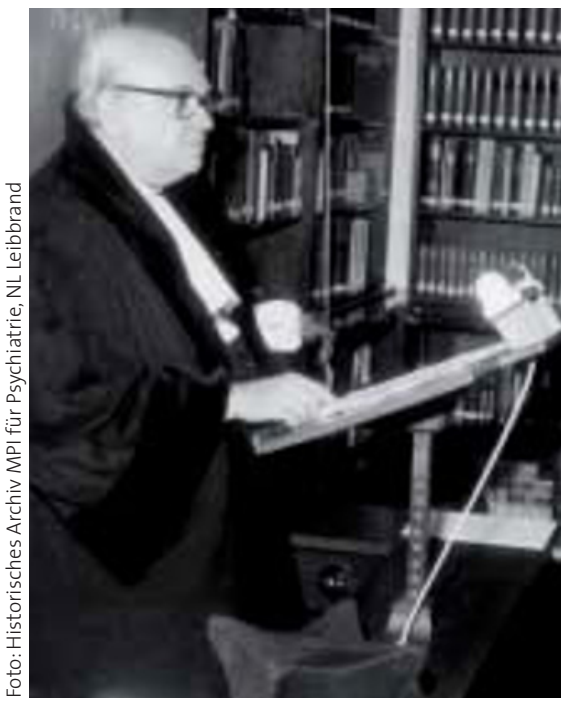

Werner Leibbrand während einer Vorlesung im Münchener Institut für Geschichte der Medizin, zirka 1965.

- Der Kaufmannssohn Werner Leibbrand wuchs in Berlin in großbürgerlichen Verhältnissen auf. Nach Studium und Klinikzeit ließ er sich als Psychiater nieder. 1925 heiratete er die Sängerin Claire Streich. Leibbrand unterhielt Kontakte zur High Society, er nahm die Rolle eines Modearztes im Berlin der „Goldenen Zwanziger“ ein.

Mit dieser Rolle gab sich Leibbrand aber nicht zufrieden: Gemeinsam mit Otto Juliusburger wirkte er in einer psychiatrischen Fürsorgestelle für Alkohol- und Drogenabhängige in den Bezirken Wedding und Tiergarten.

\section{Starkes soziales Engagement}

In den Berliner Arbeiterbezirken grassierten Geschlechtskrankheiten, Sittlichkeitsdelikte und Alkoholismus. Die medizinische Versorgung war rudimentär. Ein Engagement für die vernachlässigten Bevölkerungsgruppen brachte Ärzte stets in den Verdacht, sich zugunsten der illegalen Abtreibungen oder des gleichgeschlechtlichen Geschlechtsverkehrs zu positionieren und damit eine Gegenposition zu allen ärztlichen Fachverbänden einzunehmen.

Politischen Druck erlebte Leibbrand schon 1933, als er aus Protest gegen den Ausschluss der jüdischen Kollegen seine Mitarbeit in der ärztlichen Stan-

Medizinethiker Werner Leibbrand

\title{
Auch die Nazis konnten ihn nicht beugen
}

\begin{abstract}
Mit einer Jüdin verheiratet, von den Nazis verfolgt, nach dem Krieg Gutachter der Anklage bei den Nürnberger Prozessen: Werner Leibbrand (1896-1974) war ein sozial engagierter, festen Prinzipien folgender Arzt, der sich durch Anfeindungen von Kollegen oder politischen Druck nicht beeindrucken ließ.
\end{abstract}

desvertretung aufgekündigt hatte. Die Nationalsozialisten bekämpften ihn wegen seines sozialpolitischen Engagements und seiner (zweiten) Ehe mit der Jüdin Margarete Bergius. Im Gegensatz zu vielen seiner Kollegen ging Leibbrand nicht ins Exil. Er wurde 1943 nach Nürnberg zwangsversetzt und immer stärkeren Pressionen ausgesetzt. Im Herbst 1944 tauchte das Ehepaar Leibbrand in den Untergrund ab.

\section{Wegbereiter der Entnazifizierung}

Nach Kriegsende erwies sich Werner Leibbrand den Besatzungsbehörden als der einzige zuverlässige, nicht nationalsozialistisch gesinnte Arzt im Raum Nürnberg-Erlangen, sodass er mit der Reorganisation der psychiatrischen Kliniken beauftragt wurde. Hier zeichnete er sich durch seine Bemühungen zur Entnazifizierung aus.

Dies prädestinierte Leibbrand als einzigen deutschen Gutachter der Anklage bei den Nürnberger Ärzteprozessen. Er musste wissen, dass er sich dadurch den Hass zahlreicher Kollegen zuziehen würde und dies seiner Karriere nur schaden konnte. Seine Kollegen, auch gerade diejenigen, die den Ärzteprozess kommentierten (Mitscherlich, v. Uexküll), ignorierten Leibbrands Auftritt. Im kollektiven Gedächtnis seiner Berufsgruppe spielt er keine Rolle.

\section{Die Jahre in München}

Die Erfahrungen der Jahre bis 1945 bewegten Leibbrand dazu, sich nicht ins Privatleben zurückzuziehen, sondern im Alter von 56 Jahren als Professor für Geschichte (und Ethik) der Medizin an der Universität München einen Neuanfang zu suchen.

Leibbrand nahm mit seiner Biografie in München nahezu eine Ausnahmestellung ein. Wissenschaftlich tat sich Leibbrand durch den Wiederaufbau von Kontakten nach Frankreich und Israel hervor, für die er in diesen Ländern auch geehrt wurde.

Daneben konnte er nachweisen, dass ein Zuwachs an wissenschaftlichen Erkenntnissen in der Medizin nicht automatisch zu einem besseren ethischen Verständnis oder gesellschaftlichen Fortschritt führen musste. Seine beiden wichtigsten Werke „Der Wahnsinn“ und „Formen des Eros“ hatte Leibbrand gemeinsam mit seiner Mitarbeiterin Annemarie Wettley verfasst, die ihm 1953 als Assistentin nach München gefolgt war.

Diese hatte die Rolle einer kongenialen Mitarbeiterin eingenommen und nach dem Tod von Margarete Bergius 1962 heiratete sie Werner Leibbrand. Gemeinsam führten sie eine Vielzahl interessierter Medizinstudenten an die Geschichte des eigenen Faches heran. In ihrer Lehrtätigkeit spielte die Ethik ärztlicher Schaffenskraft stets eine zentrale Rolle.

Literatur beim Verfasser

PD Dr. phil. Florian Mildenberger

Sandstraße ga

D-80335 München

Mildenberger1973@gmx.de 